\title{
Hematocolpos on Hymeneal Imperforation: A Case Report and Literature Review
}

\author{
Farah Zidane*, Myriam Nadi, Fadwa Abdeddine, Mamoun Sebti, Sabah Amrani, Mounia Yousfi \\ and Samir Bargach \\ Department of obstetrics and gynecology, Maternity Souissi Ibn Sina, University Mohammed V Rabat, Morocco
}

*Corresponding author: Farah Zidane, Department of obstetrics and gynecology, Maternity Souissi Ibn Sina, University

Mohammed V Rabat, Morocco

\section{ARTICLE INFO \\ Received: 㟒 February 18, 2021 \\ Published: 櫘 March 01, 2021}

Citation: Farah Zidane, Myriam Nadi, Fadwa Abdeddine, Mamoun Sebti, Sabah Amrani, Mounia Yousfi, Samir Bargach. Hematocolpos on Hymeneal Imperforation: A Case Report and Literature Reviews. Biomed J Sci \& Tech Res 34(2)-2021. BJSTR. MS.ID.005526.

Keywords: Hymenal Imperforation; Hematocolpos; Amenorrhea; Hymeneotomy

\section{ABSTRACT}

Introduction: Hymenal imperforation is a rare birth defect. It produces a vulvar obstruction responsible for vaginal retention of menstrual blood. Its diagnosis and management must be early in order to preserve the subsequent fertility of the patients.

Material and Methods: We report a case of hematocolpos on hymenal imperforation hospitalized in the obstetric gynecology emergency department of the Souissi Maternity Hospital in Rabat in September 2019. The aim of our work was to analyze the diagnostic and therapeutic features of this pathology.

Results and Discussion: It emerges from this work that this anomaly is the prerogative of patients in the peri-pubertal period. The spectrum of clinical signs is dominated by abdominopelvic pain, the existence of abdomino-pelvic swelling and urinary complications such as acute urine retention, pollakiuria and dysuria. The diagnosis is mainly clinical by the discovery of perineovulvar swelling on genital examination, it is guided by ultrasound. Surgical treatment is simple. It is carried over an incision of the obturating membrane and drainage of the collection. Revision surgery is necessary in the event of hymenal restenosis.

Conclusion: Systematic screening for hymenal imperforation at birth and its early diagnosis in the face of painful primary amenorrhea can prevent its complications.

\section{Introduction}

Hymenal imperforation is a rare malformation that has been described for the first time by Ambroise Paré in 1633 [1]. It causes an obstruction of the vulvar orifice responsible for vaginal retention of menstrual blood at puberty which called: "hematocolpos". Its diagnosis seemed easy from birth by systematic screening, is usually done at puberty by inspection of external genitalia. Painful cryptomenorrhea is the most common symptom. Non-gynecological symptoms sometimes mislead the diagnostis. Ultrasound has simplified the analysis of this rare pathology and is Considered the exam of choice to confirm the diagnosis and identify a possible upstream impact and possible associated urogenital abnormalities. The treatment is exclusively surgical: "Hymeneotomy". it remains remarkably simple and led to final cure. Routine screening at birth, and early treatment are the best guarantors of prevention of complications of this pathology. We illustrate our work with a clinical case reporting the positive diagnosis for hematocolpos by hymenal imperforation and having been hospitalized in the emergency department of the Maternity Souissi in Rabat.

\section{Materials and Methods}

The clinical case is a 14 years old girl with a low social economic level, she had admitted to emergency for abdominopelvic pain, she had no medical history. there is no signs of urinary tract or digestive problems. General examination Find a conscious patient who is hemodynamically stable. Abdominal examination find A flexible abdomen with the presence of a right prlvic mass right which measerd about $10 \mathrm{~cm}$ in its large diameter without hepatosplenomegaly. Gynecological examination find A good development of the external genitalia, and secondary sex characteristics. An imperforate and bulging hymen, The rectal 
examination combined with the abdominal palpation reveals the existence of a soft, sensitive pelvic-abdominal mass varying in size from 8 to $12 \mathrm{~cm}$. a pelvic ultrasound performed which revealed: A homogeneous uterus in the normal place measuring $6 \mathrm{~cm} * 4.7 \mathrm{~cm}$, with a regular outline. The intrauterine emptiness line is clearly visible, containing a hematometry slide. In the vaginal region: we note the presence of a voluminous oblong image, of thick content measuring $122 * 78 * 77 \mathrm{~mm}$.Both ovaries are normal in size, measuring $27 * 20 \mathrm{~mm}$ at right and $22 * 15$ on the left, and normal looking. The bladder is thin-walled alithiasis; The liver, spleen and both kidneys are free from abnormalities. The diagnosis of hematocolpos was confirmed and the patient undergone a surgical treatment under general anesthesia, the intervention consists of A Y-shaped incision at the hymen to avoid the urethra. The drainage brought back 550cc of blackish blood and the Placement of an intra-vaginal bladder catheter. The course was satisfactory, without stenosis. We dilated the orifice once a week for 1 month, then, once / 15 days, then once / month for 3 months. The patient was followed regularly for a year in consultation, then was lost to follow-up (Figures 1 \& 2).

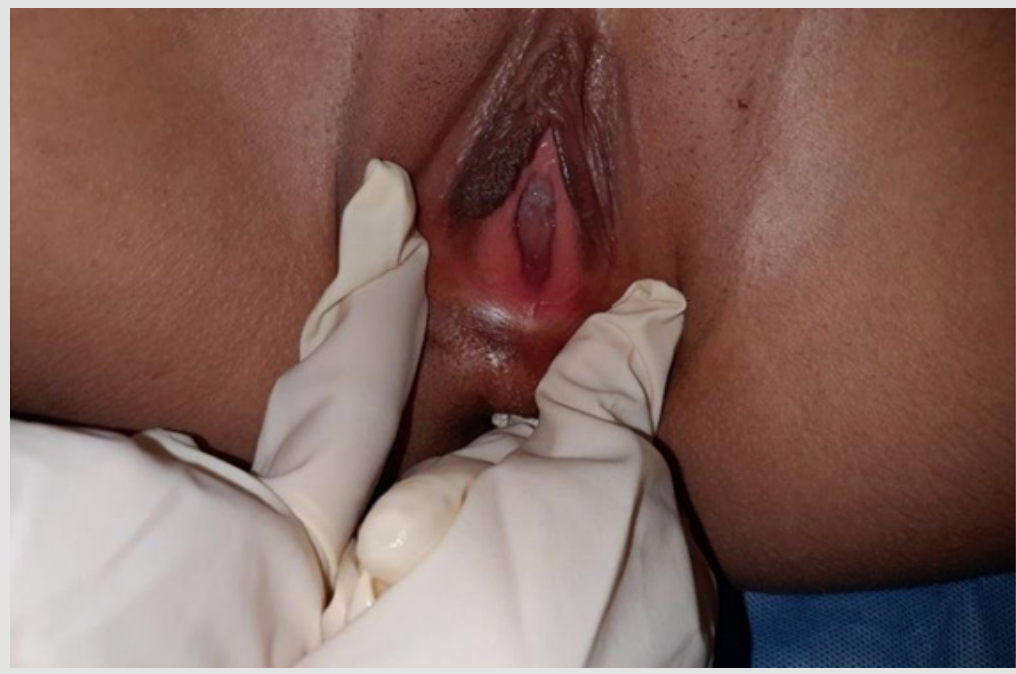

Figure 1: The bulging pale blue imperforate hymen, which completely closes the vagina.
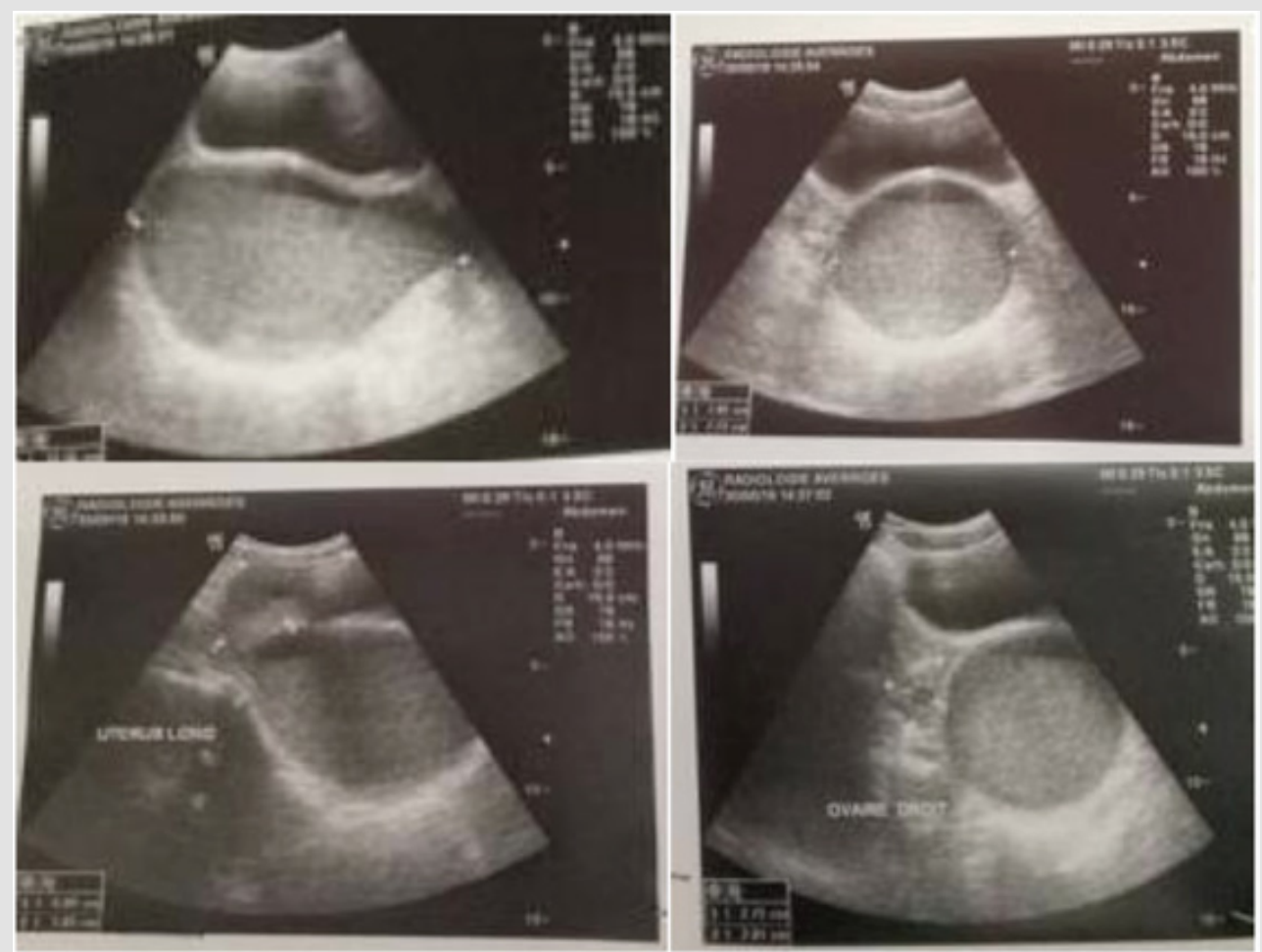

Figure 2: Suprapubic ultrasound: aspects in favor of a hematocolpos: oval collection of retrovesical fluid which communicates above with a normal size uterus. 


\section{Results and Discussion}

Clombus described for the first time in 1559, the congenital absence of the vagina. -During the tenth century Soranus and Delphus described cervical atresia [2]. -Hymenal imperforation was first described by Ambroise Paré in 1633 [1] -Hippocrates and Celsus [2,3], reported a case of vaginal obstruction by hymenal imperforation with secondaryhematocolpos. Hymenal imperforation has a frequency of $0.1 \%$ with the presence of familial cases [4]. Puberty remains the most frequent period of the hematocolpos diagnosis. The diagnosis of hymenal imperforation is possible in utero with an ultrasound finding of hydrometrocolpos [5,6]. in utero diagnosis also has the advantage of looking for associated renal malformations. This diagnosis can be made by a systematic screening at birth but also before a hydrometrocolpos during the genital crisis of the newborn female [7]. Most often, this malformation is discovered at puberty. The diagnosis must be suspected in a young girl presenting with primary amenorrhea with normally developed secondary sexual characteristics. Our patient was not yet menarche but had good development of the external genitalia, and secondary sexual characteristics. Patients usually consult for recurrent pelvic pain secondary to the accumulation of blood in the vagina or hematocolpos $[8,9]$.

The cyclic nature of painful attacks may be lacking given the usual irregularity of the menstrual cycle during the peripubertal period [9]. The pain can be deceptive, pseudo-appendicular and induce "excess" interventions for suspected acute appendicitis [10]. Hematocolpos can compress the urethra and cause dysuria, complete bladder retention or even bilateral ureterohydronephrosis $[8,11$ -
15]. Einsenberg [16] reported through a series of 44 observations of hematocoplos, 7 cases of bladder retention. Constipation comes from the same compressive mechanism [17]. Our patient presented with pelvic pain but did not report any signs of bladder or digestive compression. The blood is retained first in the vagina, then the uterus (hematometry) and possibly the tubes $[18,19]$. Its volume varies from patient to patient and can even reach 3 liters [20-22].

In case of diagnostic doubt, ultrasound may be helpful in showing the hematocolpos as a midline, retrovesical fluid-tone image containing a few heterogeneous echoes. This collection is surmounted by the communicating uterine cavity, which is often small, dilated by fluid content in the event of hematometry [23,24]. Hematosalpinx or peritoneal effusion can be found [24,25]. The ultrasound examination also analyzes uterine malformations. Renal agenesis is systematically sought, especially in cases of genital duplication [5]. Ultrasound may also show ureteropyelocalicular dilation in the event of compression of the urinary tract by hematocolpos [26,27]. In our patient, an abdominopelvic ultrasound was performed and revealed an intra-vaginal fluid collection in favor of hematocolpos. The antenatal ultrasound at 20 weeks of amenorrhea shows a collection image in the small pelvis, behind the bladder, but this mass can have several etiologies (anterior sacrococcygeal tumor, anterior sacral meningocele, ovarian cyst) $[28,29]$. Around 24 weeks of amenorrhea, following the development that the diagnosis asserts, the anterior sacral meningocele and the sacrococcygeal teratoma will develop towards the caudal region, while the ovarian cyst and hydrocolpos develop towards the cranial region [29]. The sex will be visible on this date, and the shape of the collection that will evoke the diagnosis.
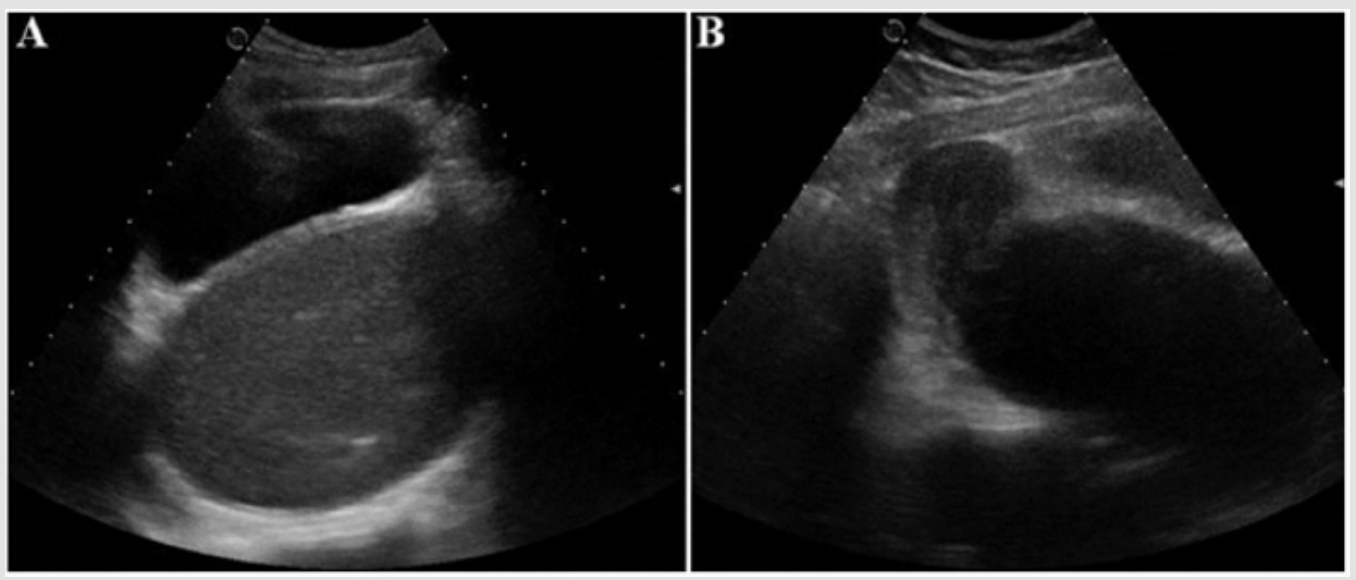

Figure 3:

A. Axial Suprapubic ultrasound: presence of a retrovesical, median, hypoechoic fluid formation containing a fine echogenic stippling

B. Sagittal section: the collection communicates at the top with the uterine cavity which is not distended.

MRI takes place in the exploration of pelvic masses and uterovaginal malformations. These advantages are especially valid in the event of difficulty of ultrasound diagnosis. It is the best complementary exploration technique, giving the T2-weighted sequences a very good anatomical morphological analysis of the malformation. T1-weighted sequences confirm haematic content in 
the vagina and in the overlying uterine horn [26,27] (Figures 3 \& 4). Congenital obstruction of the vaginal canal is a benign disease that progresses easily when properly diagnosed and treated. Ignorance of this pathology would expose to harmful complications: Urinary complications: Very common and often constitute a diagnostic circumstance. Acute urinary retention by urethral or bladder compression is often reported [30]. The distension involves the upper apparatus with ureterohydronephrosis. Infection is also reported due to stasis. Infection of vaginal retention fluid: It is a serious complication, which can be fatal and affect the fertility of patients. The vaginal infection can involve the uterine cavity with endometritis, which could progress to salpingitis, and finally pelviperitonitis. Upstream distension: The distension may involve the uterus with hematometry or hydrometry. At a more advanced stage, there is a hematosalpinx or a hydrosalpinx. Digestive complications: Rare, ranging from simple transit disorder to peritonitis by intraperitoneal passage of vaginal contents along the tubes or by rupture of a pyocolpos or rupture of the bladder [31]. Endometriotic transplants: This is a transplant of endometrial cells from menstrual tubal reflux into the pelvic peritoneum or ovary. Audbert reports a case of hematocolpos on hymenal imperforation with ovarian endometriosis and diffuse pelvic grafts [32].
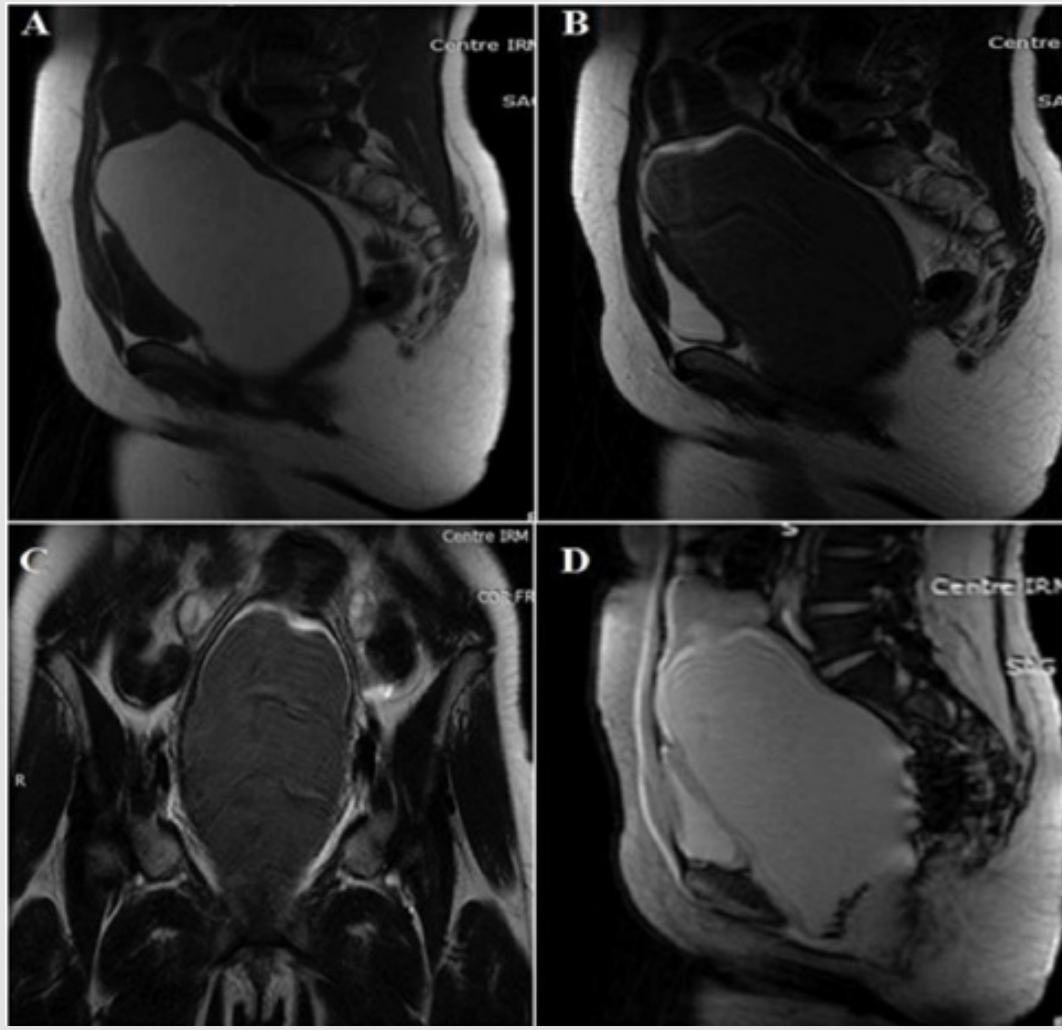

Figure 4: Pelvic MRI
A. Sagittal SE T1 sequence
B. Sagittal sequence SE T2: significant distension of the vagina with T1 hypersignal content, T2 hypointense
C. SET2 coronal sequence: the collection continues up through the uterus. The ovaries are of normal size and morphology
D. Sagittal sequence T2 gradient echo: Presence of depressing deposits in T2 hypointense *related to hemosiderin.

The treatment is limited in a large number of cases to simple drainage of the retention bag. The simple puncture: This is the first surgical procedure which will allow the placement of the Foley catheter with a possible aerobic and anaerobic bacteriological sample [5]. Aged blood is abundant and under pressure. It especially retains a preoperative diagnostic interest and also allows to deflate a very large pocket. The cruciform incision consists of incising the obturating membrane in a cross, which allows good drainage, which will be maintained using a drain left in place until the secretions have dried up. Graber's radial incision: This technique begins with the incision of the hymen with a central hymenectomy and evacuation of the haematic collection, it continues with the radiar incisions of the hymeneal ring [33,34]. Hemostasis occurs in stitches separated from the $4 / 0$ absorbable suture (Vicryl). The caliber will be maintained by a drain to avoid scarring, sometimes in a fibrous ring. This technique does not guarantee virginity. Caparo incision: This is an extremely simple technique allowing a sagittal hymenal section, and generally does not pose the problem 
of overlying collection drainage. It gives a lipped hymen. This is the only technique that retains virginity. Elliptical excision: Drainage follow-up for 3 to 7 days. This technique would expose to vicious scars like sclerosis and orificial dyspareunia.

Pozzi technique: Consists of incising the hymen and the constrictor muscles at 5 and 7 o'clock radially. The constrictor muscles of the vulva are incised transversely and sutured circularly at separate points. This plastic device aims to enlarge the vaginal opening. $\mathrm{CO}_{2}$ laser treatment technique: It has been proposed by some authors. The $\mathrm{CO}_{2}$ laser is a laser in which the gaseous medium consists of a mixture of carbon dioxide, nitrogen and helium. The $\mathrm{CO}_{2}$ laser can be used like a scalpel. Two technical precautions are fundamental for any hymeneotomy: Observe the openings of the Bartholin glands at 5 a.m. and 7 a.m. Incise at 11 a.m. and at 1 a.m. to free the lower edge of the urinary meatus, and ensure a meatohymenal separation. For some authors, they suggest performing the gesture using a Foley catheter, the balloon of which is inflated $\left(10 \mathrm{~cm}^{3}\right)$ in the vaginal cavity, which makes it possible to control the incision in order to preserve the integrity of the the hymenal ring. This balloon also allows the hymen to be spread in order to electively achieve hemostasis and prevent re-bonding of the hymenal margins leading to secondary stenosis $[35,36]$. The risk of recurrence with hymenal occlusion is approximately $3 \%$, according to the longest published series of 65 patients [34]. The prognosis immediately after surgical treatment is satisfactory with the pelvic pain subsiding. Complications in this period are dominated by infection which can be prevented with antibiotic therapy. Prolonged surveillance of these girls is important. An assessment of the repair is usually done 2 or 3 weeks after the procedure. The vulvar patency allowing the onset of menstruation in girls of puberty is a sign of healing. Hymenal ring sclerosis has been reported in a study by Castaigne and Haddad on 9 patients operated on for hymenal imperforation [37-39].

\section{Conclusion}

Hematocolpos on hymenal imperforation is a rare condition which must be mentioned before any acute abdomino-pelvic pain syndrome or pelvic mass of the girl in the puberty period not yet regulated, especially as the pains are cyclical and the development of characters secondary sex is normal. It is an often benign condition, of favorable evolution, if it is diagnosed and treated early. Conversely its ignorance, exposes to serious complications. Imaging guide the diagnosis, look for any associated uro-genital malformations and signs of compression, especially urinary tract. The treatment is exclusively surgical. Prevention by careful examination of the genitals at birth is possible.

\section{References}

1. Yanza MC, Sepou A, Nguembi E, Ngbale R, Gaunefet C, etal. (2003) Hymen imperforé, diagnostic négligé à la naissance, urgence chirurgicale à l’adolescence. Schweiz Med Forum 44: 1063-1065.
2. EL Mamoun M (1985) Hydrométrocolpos et hématocolpos de l'enfant. Thèse de médecine Rabat p. 528.

3. Messina M, Severi Fm, Bocchi C, Ferrucci E, Di Maggio D, et al. (2004) Voluminous prénatal masse: a case f congénital hydrometrocolpos. J Matern Fetal Neonatal Med 15(2): 135-137.

4. Heger AH, Ticson L, Guerra L, Julie Lister FNP, Toni Zaragogoza FNP, et al. (2002) Appearance of the genitalia in girls selected for nonabuse: review of hymenal morphology and nonspecific findings. J Pediatr Adolesc Gynecol 15(1): 27-35.

5. Salvat J, Slamani L (1998) Hématocolpos. J Gynécol Obstet Biol Reprod 27(4): 396-402.

6. Winderl LM, Silverman PK (1995) Prenatal diagnosis of congenital imperforate hymen. Obstet Gynecol 85(5): 857-860.

7. Rochet Y (1986) The principal genital malformations. Therapeutic aspects. Rev Fr Gyn Obstet 81(5): 315-317.

8. Adali E, Kurdoglu M, Yildizhan R, Kolusari A (2009) An overlooked cause of acute urinary retention in an adolescent girl: a case report. Arch Gynecol Obstet 279(5): 701-703.

9. Paniel BJ, Truc JB (1987) Diagnostic des malformations congénitales de la vulve et du vagin. Ann Pédiatr 34: 11-25.

10. Emans SJ, Laufer MR, Goldstein DP (2004) Dysmenorrhea, pelvic pain, and the premenstrual syndrome. In: Emans SJ, Laufer MR, Goldstein DP (Eds.).), Pediatric and Adolescent Gynecology ( $5^{\text {th }}$ Edn.). LippincottRaven, Philadelphia, USA, pp. 376-384.

11. Loscalzo IL, Catapano M, Loscalzo J, Sama A (1995) Imperforate hymen with bilateral hydronephrosis: an unusual emergency department diagnosis. J Emerg Med 13(3): 337-339.

12. Yu TJ, Lin MC (1993) Acute urinary retention in two patients with imperforate hymen. Scand J Urol Nephrol 27(4): 543-544.

13. Dane C, Dane B, Erginbas M, Cetin A (2007) Imperforate hymen-a rare cause of abdominal pain: two cases and review of the literature. J Pediatr Adolesc Gynecol 20(4): 245-247.

14. Wort SJ, Heman-Ackah C, Davies A (1995) Acute urinary retention in the young female. Br J Urol 76(5): 667.

15. Chang JW, Yang LY, Wang HH, Wang JK, Tiu CM (2007) Acute urinary retention as the presentation of imperforate hymen. J Chin Med Assoc 70(12): 559-561.

16. Einsenberg E, Faber M (1982) Complete duplication of the uterus and cervix with unilateraly imperforate vagina. Obst Gynecol 60(2): 259262.

17. Wang W, Chen MH, Yang W, Hwang DL (2004) Imperforate hymen presenting with chronic constipation and lumbago: report of one case. Acta Paediatr Taiwan 45(6): 340-342.

18. Olive DL, Henderson DY (1987) Endometriosis and mullerian anomalies. Obstet Gynecol 69: 412-415.

19. Rock JA, Zacur HA, Dlugi AM, Jones HW, Te Linde RW, et al. (1982) Pregnancy success following surgical correction of imperforate hymen and complete transverse vaginal septum. Obstet Gynecol 59(4): 448451.

20. Liang CC, Chang SD, Soong YK (2003) Long-term follow-up of women who underwent surgical correction for imperforate hymen. Arch Gynecol Obstet 269(1): 5-8.

21. Joki-Erkkilä MM, Heinonen PK (2003) Presenting and long-term clinical implications and fecundity in females with obstructing vaginal malformations. J Pediatr Adolesc Gynecol 16(5): 307-312.

22. Sakalkale R, Samarakkody U (2005) Familial occurrence of imperforate hymen. J Pediatr Adolesc Gynecol 18(6): 427-429. 
23. Robberecht E, Smets A, Wincker MV, Delens F (1996) Radiological case of the month hematocolpos due to imperforate hymen. Arch Pediatr Adolesc Med 150(9): 993-994.

24. Nohuz E, Moreno W, Varga J, Tamburro S, Yanez M, et al. (2010) Imperforate hymen: one diagnosis can hide another. Archives de Pédiatrie 17(4): 394-397.

25. Genevois A, Marouteau N, Lemercier E, Dacher JN, Thiebot J (2008) Acute pelvic pain imaging. J Radiol 89(1): 92-106.

26. Gyimadu A, Sayal B, Guven S, Serder Gulnap G (2009) Hematocolpos causing severe urinary retention in an adolescent girl with imperforate hymen: an uncommon presentation. Arch Gynecol Obstet 280(3): 461463.

27. Kapsalaki E, Daponte A, Deligeoroglou E, Zavos A, Fezoulidis IV, et al. (2011) The role of MRI in young adolescent girls with hematocolpos. European Journal of Radiology Extra 78(2): 97-100.

28. Chelli D, Kehila M, Sfar E, Zouaoui B, Chelli H, et al. (2008) Imperforation hyménéale: peut-on la traiter en préservant la virginité. Santé 18: 83-87.

29. De bryn R (2007) Appareil génital féminin. In: De Bryun R (Edt.,)., échographie pédiatrique: indications, techniques, et résultats. Elsevier Masson, Paris, France, pp. 189-212.

30. Brevetti LS, Kimura K, Brevetti GR, Lawrence JP, Soper RT (1997) Pyocolpos: diagnosis and treatement. Journal of pediatric surgery 32(1): 110-111.

31. Lalla Malika MM (2000) Hydrocolpos et hématocolpos à propos de 11 cas. Thèse de médecine -Rabat.

ISSN: 2574-1241

DOI: 10.26717/BJSTR.2021.34.005526

Farah Zidane. Biomed J Sci \& Tech Res

(C) $(9)$ This work is licensed under Creative

Submission Link: https://biomedres.us/submit-manuscript.php
32. Audbert AJM (1984) Arne- Chalus: Endométriose. Ann Pédiatrie Mars, p. 31.

33. Ali A, Cetin C, Nedim C, Kazim G, Cemalettin A (2003) Treatment of imperforate hymen by application of Foley catheter. Eur J Obstet Gynecol Reprod Biol 106(1): 72-75.

34. Acar A, Balci O, Karatayli R, Capar M, Colakoglu MC (2007) The treatment of 65 women with imperforate hymen by a central incision and application of Foley catheter. BJOG 114(11): 1376-1379.

35. Robberecht E, Smets A, Wincker MV, Delens F (1996) Radiological case of the month hematocolpos due to imperforate hymen. Arch Pediatr Adolesc Med 150(9): 993-994.

36. Afiffi A, Bouabdellah Y, Etaybi F, Benhamou M (2006) Hydrocolpos néonatal à propos de quatre cas. Journal de pédiatrie et de périculture 19(8): 328-330.

37. Haddad B, Barranger E, Paniel BJ (1999) Blind hemivagina: long-term followup and reproductive performance in 42 cases. Hum Reprod 14(8): 1962-1964.

38. Eftychia k, Alexandros D, Efthimos D, Apostolos Z, Lommis F, et al. (2011) The role of IRM in young adolescent girls with hematocolpos. European Journal of Radiology Extra 78(2): e97- e100.

39. Salem A, Yahyaoui S, Messoud A, El Mhabrech H, Faleh R, et al. (2014) Masse pelvienne chez une jeune fille: penser à l'hématocolpos. Pan African Medical Journal 17: 84

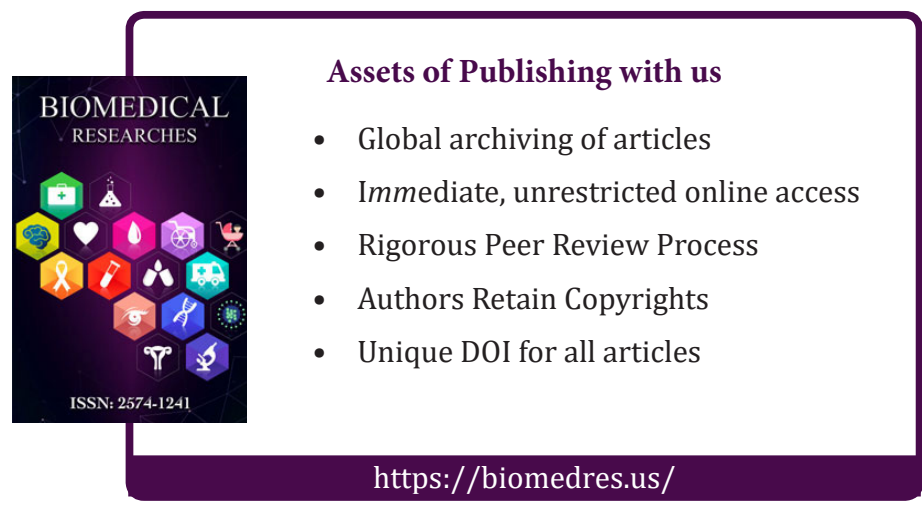

